Prepared for the U.S. Department of Energy under Contract DE-AC05-76RL01830

\title{
Final Report on Isotope Ratio Techniques for Light Water Reactors
}

DC Gerlach

CJ Gesh

DE Hurley

July 2009
MR Mitchell

GH Meriwether

BD Reid 


\title{
Final Report on Isotope Ratio Techniques for Light Water Reactors
}

\author{
DC Gerlach MR Mitchell \\ CJ Gesh GH Meriwether \\ DE Hurley BD Reid
}

July 2009

Prepared for

the U.S. Department of Energy

under Contract DE-AC05-76RL01830

Pacific Northwest National Laboratory

Richland, Washington 99352 


\section{Abstract}

The Isotope Ratio Method (IRM) is a technique for estimating the energy or plutonium production in a fission reactor by measuring isotope ratios in non-fuel reactor components. The isotope ratios in these components can then be directly related to the cumulative energy production with standard reactor modeling methods.

All reactor materials contain trace elemental impurities at parts per million levels, and the isotopes of these elements are transmuted by neutron irradiation in a predictable manner. While measuring the change in a particular isotope's concentration is possible, it is difficult to correlate to energy production because the initial concentration of that element may not be known. However, if the ratio of two isotopes of the same element can be measured, the energy production can then be determined without knowing the absolute concentration of that impurity since the initial natural ratio is known. This is the fundamental principle underlying the IRM. Extremely sensitive mass-spectrometric methods are currently available that allow accurate measurements of the impurity isotope ratios in a sample. Additionally, indicator elements with stable activation products have been identified so that their post-irradiation isotope ratios remain constant.

This method has been successfully demonstrated on graphite-moderated reactors. Graphite reactors are particularly well-suited to such analyses since the graphite moderator is resident in the fuel region of the core for the entire period of operation. Applying this method to other reactor types is more difficult since the resident portions of the reactor structure available for sampling are either outside the active core or non-cladding structural parts of individual fuel assemblies. The goal of this research is to evaluate whether the IRM can produce meaningful results for light water-moderated reactors and to propose the design of a fuel assembly monitor that would simplify sampling and analysis.

In this paper, we use the IRM to estimate the energy production in one specific light water moderated reactor - a boiling water reactor (BWR) based upon measurements taken from a fuel assembly channel. These channels, like the cladding and structural materials of the fuel assembly, is made of Zircaloy, either Zircaloy -2 or Zircaloy -4 . Both of these alloys have been used in both pressurized water and boiling water reactors throughout the history of the domestic US nuclear industry.

Our preliminary results are in good agreement with the actual operating history of the reactor during the time the fuel assembly channel was resident in the core. We will also present chemical analysis protocols, identify potential materials for purpose-built fluence monitors, and present a fluence monitor design that may be suitable for a commercial power reactor. 



\section{Contents}

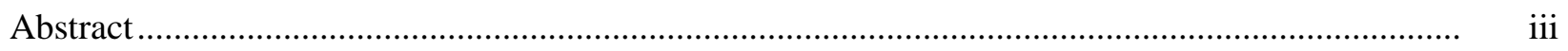

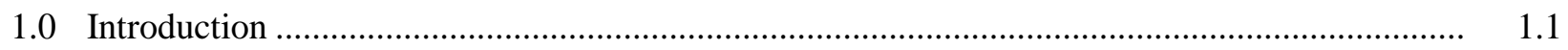

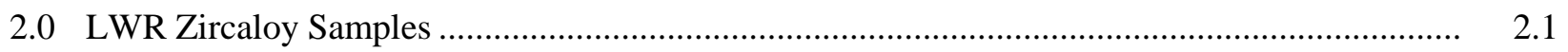

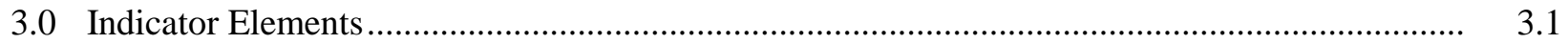

3.1 Initial SIMS Results on Impurity Elements in Unirradiated Samples.............................. 3.1

3.2 SIMS Results on Impurity Elements in Irradiated Samples ............................................. 3.2

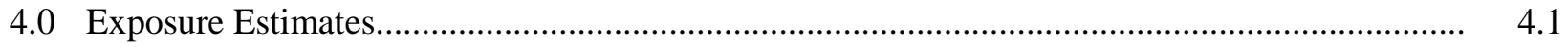

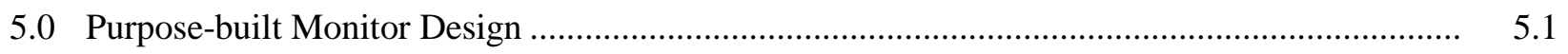

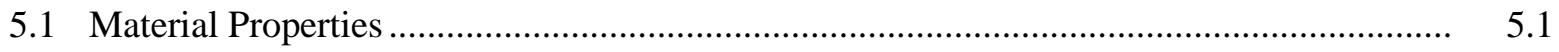

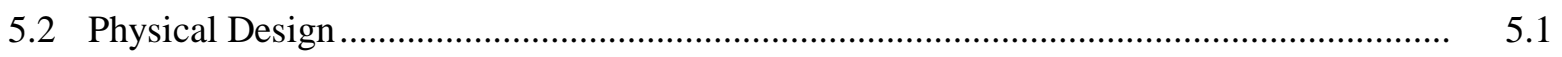

6.0 Theoretical Studies of Purpose-Built Monitor Designs ...........................................................

6.1 Specific Recommended Analytical SIMS Protocols for Optimized Monitors..................... $\quad 6.1$

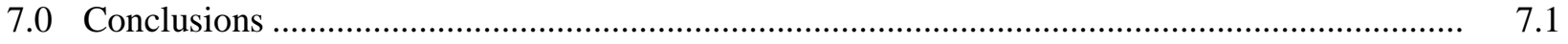

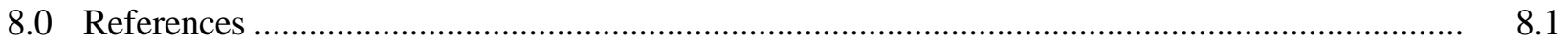




\section{Figures}

2.1. The image above shows where a 0.008 -inch-thick slice was made, from which six discs suitable for both SIMS and electron microscopy analysis were cut.

3.1. Exposure Estimates for Sample LSA-A3 as a Function of Water Density.

4.1. ${ }^{179} \mathrm{Hf} /{ }^{176} \mathrm{Hf}$ Ratio as a Function of adjacent Fuel Exposure..

4.2. WIMS Calculated ${ }^{56} \mathrm{Fe} /{ }^{57} \mathrm{Fe}$ Versus ${ }^{178} \mathrm{Hf} /{ }^{176} \mathrm{Hf}$ with Measured Data......

5.1. Upper Nozzle of VVER Fuel Assembly

\section{Tables}

3.1. IRM (Impurity) Indicator Elements Used in Previous Work ................................................ 3.1

3.2. Measured Indicator Isotope Ratios and Standard Errors ..................................................... 3.3

3.3. Candidate Elements and Isotopes for Purpose-Built Monitors ............................................... 3.4

4.1. Generic 10×10 BWR Bundle ......................................................................................

4.2. Estimated Sample Exposure (GWd/MT) by Indicator Ratio ................................................. 4.4

4.3. Average Estimated Sample Exposure (GWd/MT) .................................................................... 


\subsection{Introduction}

The measurement of characteristic radiation from fission products or activation products has long been used to infer neutron fluence for a wide variety of applications. Only recently, however, have mass spectrometric methods capable of measuring isotope ratios of extremely low concentration impurity elements become available. In the mid-1990s, an effort was undertaken at Pacific Northwest National Laboratory to develop a technology for verifying plutonium production in graphite-moderated reactors (Gerlach et al. 1998, Gesh 2004, Reid et al. 1999). ${ }^{\text {(a) }}$ The technique developed, known as the Graphite Isotope Ratio Method (GIRM), was based on the fact that neutrons produced from fission reactions are also parasitically absorbed in non-fuel components such as reactor structural material, control rods, coolant, and the graphite moderator. The fluence in these non-fuel components is proportional to the total number of fissions that have occurred in the fuel. This, in turn, can be directly related to the total plutonium production in the reactor. Therefore, if the fluence in the graphite can be determined, the cumulative plutonium production can be inferred.

Even the highest purity, reactor-grade graphite contains elemental impurities at parts per million levels, and the isotopes of these elements are transmuted by neutron irradiation in a predictable manner. While measuring the change in a particular isotope's concentration is possible, it is difficult to correlate to energy or plutonium production because the initial concentration of that element may not be known. However, if the ratio of two isotopes of the same element can be measured, the fluence can then be determined without knowing the absolute concentration of that element since the initial ratio is simply the natural ratio. This is the fundamental principle underlying the GIRM. A key advantage of this method compared to more traditional activation analysis is that numerous indicator elements with stable activation products have been identified so that their isotope ratios remain constant after irradiation.

Graphite reactors possess several characteristics that make this method particularly appealing. The concentrations of key impurity elements are so low that they do not perturb the spatial or energy flux shape in the graphite - that is, they are infinitely dilute. The underlying physics of graphite reactors results in flux profiles that are relatively smooth. Most importantly, the graphite moderator is resident in the core for the entire lifetime of the reactor-it provides a permanent record of reactor operation. This method has been successfully demonstrated (Reid et al. 1999) and can produce accurate plutonium production estimates.

The goal of our current work is to evaluate the effectiveness of this technique for light water moderated power reactors. Since the structural components of such reactors available for sampling are mainly outside of the active fuel or part of the fuel assembly structure, the sampling and analysis is more complicated, nevertheless, meaningful results can be obtained. Additionally, we will propose a purposebuilt fluence monitor design that would simplify the IRM sampling and analysis of LWRs. A key benefit of a purpose-built monitor is that rather than analyzing trace elements in a bulk material, we will be able to make the entire monitor out of suitable indicator elements, vastly simplifying the mass spectrometry measurements.

(a) Reid BD, DC Gerlach, PG Heasler, JV and Livingston. 1997. Trawsfynydd Plutonium Estimate. Unpublished PNNL Report, Pacific Northwest National Laboratory, Richland, Washington. 
In this paper, we use the IRM to estimate the energy production in one specific light water moderated reactor - a boiling water reactor (BWR) based upon measurements taken from a fuel assembly channel. These channels, like the cladding and structural materials of the fuel assembly, is made of Zircaloy, either Zircaloy -2 or Zircaloy -4 . Both of these alloys have been used in both pressurized water and boiling water reactors throughout most of the history of the domestic US nuclear industry.

The primary application envisioned for the earlier work was the verification of declared reactor operations for non-proliferation purposes. As such, "meaningful results" can mean a variety of things. In the case of graphite production reactors, the goal has been to estimate the cumulative plutonium produced in a reactor to within a few percent. In the case of power reactors, simply confirming declared operations in a broad sense and detecting relatively major deviations, such as the large-scale replacement of reflector material with plutonium- or tritium-producing targets.

There are other possible applications for this technology. One of the most appealing is confirming the burnup of spent fuel. By analyzing samples from, for example, grid strap locations, the axial burnup profile of a fuel assembly could be accurately determined. Thus far, we have verified that suitable indicator elements are present in measurable quantities in the zircaloy samples we have studied.

In the remainder of this paper, we will discuss our sampling and measurement campaign, review the preliminary IRM modeling effort, present preliminary results, and provide some conclusions and our plans for future work. 


\subsection{LWR Zircaloy Samples}

Samples of irradiated Zircaloy were obtained from a reactor fuel vendor; these included both Zircaloy-2 and Zircaloy-4 alloys. These samples were cut from the channels that surround Boiling Water Reactor (BWR) fuel assemblies during irradiation. These samples came from two different BWR reactors in commercial service and were originally collected by AREVA to study channel bowing issues. However, these samples were ideally suited for the work under this project. The declared range of the assembly average exposure was approximately 35 to $44 \mathrm{GWd} / \mathrm{MT}$. The samples were supplied with ID numbers indicating which reactor plant they came from and the spatial relationship between the sample and the nearest reactor control rod, and were taken from locations 78 inches from the bottom of the assembly. One sample is shown in Fig. 2.1 below:
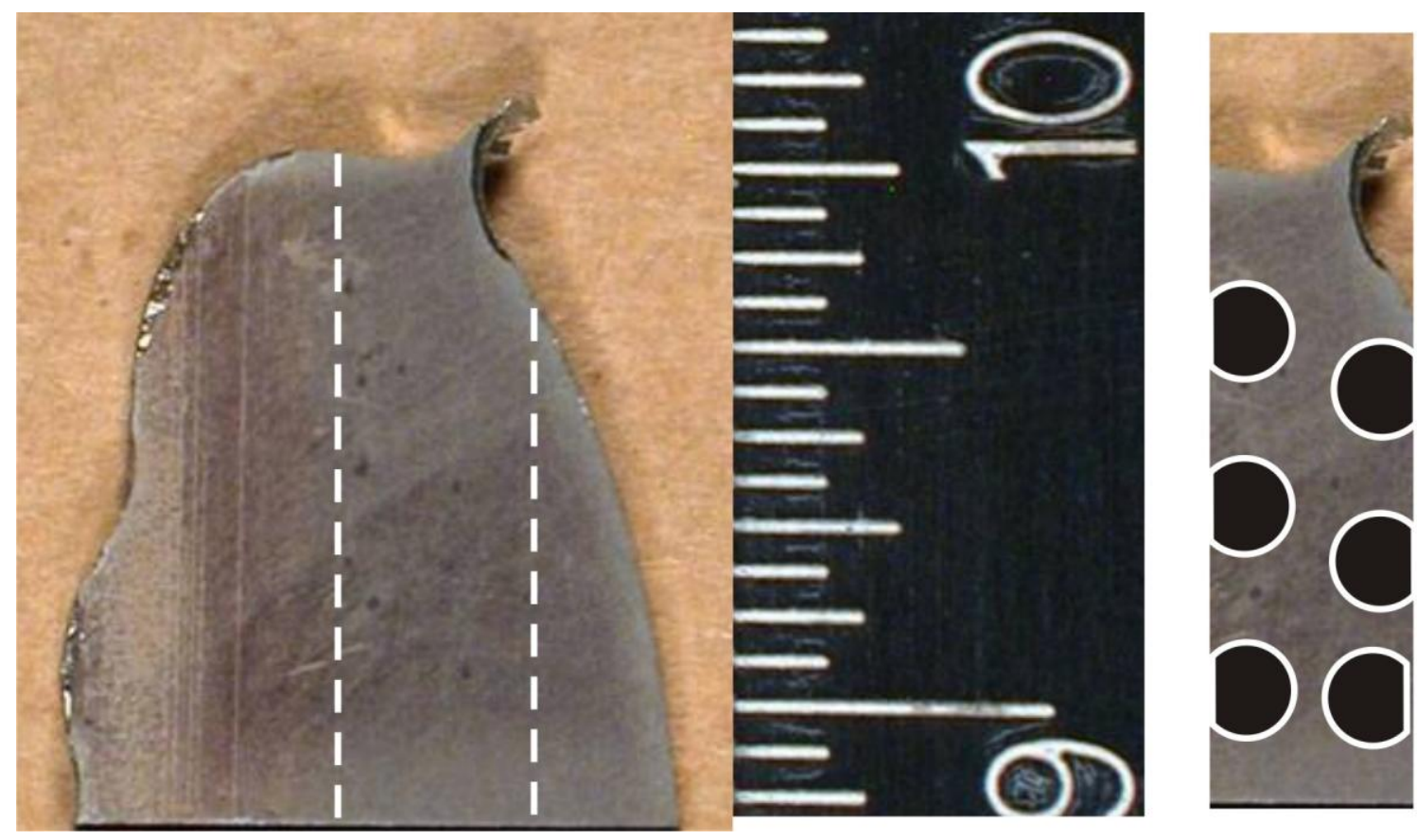

Figure 2.1. The image above shows where a 0.008-inch-thick slice was made, from which six discs suitable for both SIMS and electron microscopy analysis were cut. 


\subsection{Indicator Elements}

The first step in an IRM analysis is to identify suitable indicator elements. Indicator elements should exist in sufficient quantities to be accurately measured, have stable activation products, and have crosssections of suitable magnitude to result in meaningful isotope ratio changes for the fluence range in question. For high-fluence reactors, the $\mathrm{Ti}^{48} / \mathrm{Ti}^{49}$ ratio has been used successfully. For low-fluence measurements, the $\mathrm{B}^{10} / \mathrm{B}^{11}$ ratio is an excellent indicator element. The $\mathrm{Cl}^{36} / \mathrm{Cl}^{35}$ ratio has been effective for intermediate fluence measurements. A wide variety of uranium and plutonium ratios is appropriate for both low- and high-fluence applications. The use of multiple indicator elements, such as boron and chlorine measured in the same sample, tends to reduce the overall uncertainty associated with an IRM analysis. Table 3.1 summarizes the properties of several indicator elements found to be useful in previous work. The applicable 2200 meter/second cross sections, in units of barns (b) (Walker et al. 1989) are shown in parenthesis for all but the U/Pu isotopes since their neutron absorption characteristics cannot be defined by a single cross section.

Table 3.1. IRM (Impurity) Indicator Elements Used in Previous Work

\begin{tabular}{lcl}
\hline Element & Key Isotope Ratios & Fluence Range \\
\hline Boron & ${ }^{10} \mathrm{~B} /{ }^{11} \mathrm{~B}$ & Low (3838b) \\
Lithium & ${ }^{6} \mathrm{Li} /{ }^{7} \mathrm{Li}$ & Low-Intermediate (941b) \\
Chlorine & ${ }^{36} \mathrm{Cl} /{ }^{35} \mathrm{Cl}$ & Intermediate (43.6b) \\
Titanium & ${ }^{48} \mathrm{Ti} /{ }^{49} \mathrm{Ti}$ & Intermediate-High (7.9b) \\
Uranium & ${ }^{235} \mathrm{U} /{ }^{238} \mathrm{U},{ }^{236} \mathrm{U} /{ }^{238} \mathrm{U}$ & Low-High \\
Plutonium & ${ }^{240} \mathrm{Pu} /{ }^{239} \mathrm{Pu},{ }^{241} \mathrm{Pu} /{ }^{239} \mathrm{Pu},{ }^{242} \mathrm{Pu} /{ }^{239} \mathrm{Pu}$ & Low-High \\
\hline
\end{tabular}

\subsection{Initial SIMS Results on Impurity Elements in Unirradiated Samples}

The most useful isotope ratio for determining irradiation levels identified in previous work on graphite and aluminum is ${ }^{49} \mathrm{Ti} /{ }^{48} \mathrm{Ti}$ because it varies strongly with irradiation and is reasonably easy to resolve using the SIMS technique (Reid et al. 2001). Other Ti isotope ratios (e.g., ${ }^{46} \mathrm{Ti} /{ }^{48} \mathrm{Ti},{ }^{47} \mathrm{Ti} /{ }^{48} \mathrm{Ti}$ ) change much more slowly with burnup and are not very useful or have isobaric interference with other impurity elements $\left({ }^{50} \mathrm{Ti}\right.$ vs. ${ }^{50} \mathrm{~V}$ vs. $\left.{ }^{50} \mathrm{Cr}\right)$. The ${ }^{91} \mathrm{Zr}^{+2}$ interference gives rise to a very constant and stable ion signal occurring at an easily resolved half-mass position. This interference is included in each analysis to correct the ${ }^{48} \mathrm{Ti}$ ion count rate by subtracting the signal from the doubly charged ${ }^{96} \mathrm{Zr}^{+2}$ ions (which have the same charge-to-mass ratio). 


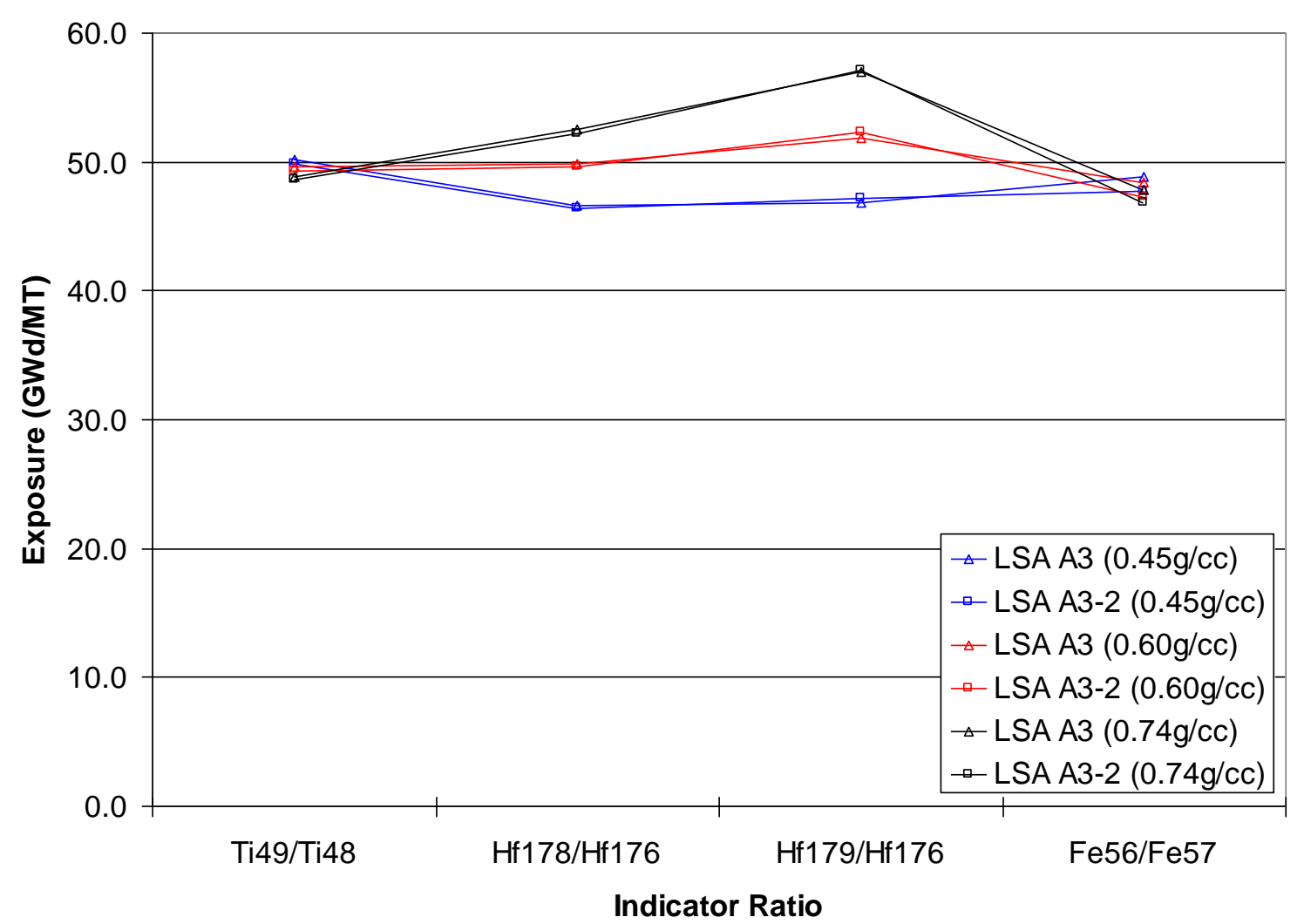

Figure 3.1. Exposure Estimates for Sample LSA-A3 as a Function of Water Density

\subsection{SIMS Results on Impurity Elements in Irradiated Samples}

Previous work with graphite had shown ${ }^{49} \mathrm{Ti} /{ }^{48} \mathrm{Ti}$ ratios to be useful in measuring neutron exposure. The initial ${ }^{49} \mathrm{Ti} /{ }^{48} \mathrm{Ti}$ ratios measured in fuel vendor irradiated samples initially seemed close to natural values in each analysis spot because ${ }^{48} \mathrm{Ca}$ and ${ }^{24} \mathrm{Mg}^{2+}$ ions contributed to ion counts at mass 48 . The Ca and $\mathrm{Mg}$ ion signals usually decreased to near-negligible levels after 30 minutes or more of presputtering in the SIMS and the removal of surface contamination with the SIMS primary ion beam. Occasionally, however, increases were observed at some depth in samples, which appear to indicate impurity inclusions with elevated contents of these elements. Small inclusions higher in Ti, relative to the baseline or matrix impurity levels, were also observed at times. It is possible that some surficial $\mathrm{Ca}$ and $\mathrm{Mg}$ were added during sample handling and mounting. It may also be possible that the fuel vendor $\mathrm{Zr}$ alloy samples were either not as pure or homogeneous as the vendor-supplied $\mathrm{Zr}-2$ and $\mathrm{Zr}-4$ samples, or that impurities were added during exposure in the reactor or during extraction from the reactor. Compared with ${ }^{49} \mathrm{Ti} /{ }^{48} \mathrm{Ti}$ ratios determined in the unirradiated $\mathrm{Zr}-2$ and $\mathrm{Zr}$-4 vendor-supplied samples, ${ }^{49} \mathrm{Ti} /{ }^{48} \mathrm{Ti}$ ratios determined in all of the irradiated fuel vendor samples were, as expected, (after corrections for the above-discussed interferences) substantially higher than natural Ti ratios (Table 3.2) and clearly indicate changes with neutron fluence exposure and fuel burnup. 
Table 3.2. Measured Indicator Isotope Ratios and Standard Errors

\begin{tabular}{ccccccccc}
\hline Sample ID & ${ }^{49} \mathrm{Ti} /{ }^{48} \mathrm{Ti}$ & $2 \mathrm{SE}$ & ${ }^{178} \mathrm{Hf} /{ }^{176} \mathrm{Hf}$ & $2 \mathrm{SE}$ & ${ }^{179} \mathrm{Hf} /{ }^{176} \mathrm{Hf}$ & $2 \mathrm{SE}$ & ${ }^{56} \mathrm{Fe} /{ }^{57} \mathrm{Fe}$ & $2 \mathrm{SE}$ \\
\hline LSA A3 & 0.1125 & 0.0008 & 2.349 & 0.032 & 13.98 & 0.27 & 28.60 & 0.22 \\
LSA A3-2 & 0.1123 & 0.0041 & 2.368 & 0.035 & 14.04 & 0.17 & 28.87 & 0.28 \\
LSA A4 & 0.1122 & 0.0004 & 2.745 & 0.131 & 13.76 & 0.35 & 30.77 & 0.31 \\
LSA C1 & 0.0999 & 0.0003 & 3.564 & 0.082 & 11.68 & 0.28 & 31.87 & 0.66 \\
LSA C1-1 & 0.0999 & 0.0003 & 3.541 & 0.055 & 11.70 & 0.27 & 32.02 & 0.34 \\
LSA C1-2 & 0.1002 & 0.0006 & 3.561 & 0.090 & 11.71 & 0.26 & 31.99 & 0.32 \\
LSA C3 & 0.0978 & 0.0007 & 3.757 & 0.102 & 11.47 & 0.17 & 32.62 & 0.58 \\
SUS 23C & 0.1176 & 0.0015 & 2.706 & 0.146 & 13.06 & 0.35 & 27.79 & 0.77 \\
SUS 33A & 0.0963 & 0.0020 & 3.618 & 0.077 & 11.96 & 0.25 & 33.14 & 1.14 \\
SUS33C & 0.1087 & 0.0032 & 3.052 & 0.028 & 12.52 & 0.24 & 30.20 & 0.42 \\
\hline
\end{tabular}

While we have demonstrated that existing impurities, particularly titanium, can generally be used to estimate the fluence that an LWR fuel assembly has been exposed to, this requires a skilled SIMS operator and each sample takes several hours to analyze. A purpose-built fluence monitor could provide quicker analysis, possibly allowing analysis to be done in the field using recently developed miniaturized SIMS. Based on our current studies on the Zircaloy samples, other indicator elements were identified as candidates for purpose-built fluence monitors. Elements such as Fe were easily detectable and were free from any serious interferences, whereas other elements such as Hf in the zircaloy samples required special analytical settings to overcome interferences affecting isotope ratio measurements.

Other candidate elements and isotopes considered in the study are listed in Table 3.3. Candidate elements selected had to have at least two stable isotopes, not produce significant amounts of radioactive isotopes, be easily analyzed by SIMS, and have neutron cross-sections consistent with a significant change in ratio over a 60 to $100 \mathrm{GWd} / \mathrm{MT}$ fuel assembly irradiation. Purpose-designed monitors would preferably be made of a high-purity sample of one of these elements, or an alloy containing two or more of these elements. For example, an Hf-Ti alloy with small amounts of Fe, but ppm levels of $\mathrm{Zr}$, would be ideal. Impurity elements in some cases may be advantageous, such as Os impurities in W or Pt used for monitors. 
Table 3.3. Candidate Elements and Isotopes for Purpose-Built Monitors

\begin{tabular}{|c|c|c|c|c|}
\hline Element & Stable Isotopes & $\begin{array}{c}\text { Best } \\
\text { Measurable } \\
\text { Ratio(s) }\end{array}$ & $\mathrm{R}(0) / \mathrm{R}(60 \mathrm{GWd} / \mathrm{MT})^{(\mathrm{a})}$ & Corrosion Resistance \\
\hline Iron & $54,56,57,58$ & $57 / 56$ & 0.586 & Poor \\
\hline Hafnium & $\begin{array}{l}174,176,177 \\
178,179,180\end{array}$ & $178 / 176$ & 0.172 & Good \\
\hline Osmium & $\begin{array}{c}184,186,187 \\
188,189,190 \\
192\end{array}$ & 190/192 & 0.713 & Poor \\
\hline Platinum & $\begin{array}{r}190,192,194 \\
195,196,198\end{array}$ & $196 / 195$ & 0.368 & Good \\
\hline Titanium & $\begin{array}{c}46,47,48,49 \\
50\end{array}$ & $49 / 48$ & 0.583 & Good \\
\hline Tungsten & $\begin{array}{c}180,182,183 \\
184,186\end{array}$ & 184/182 & 0.032 & Fair \\
\hline
\end{tabular}

(a) Smaller numbers here indicate a greater change in the isotope ratio. Assuming there are no difficulties measuring these ratios, the smaller number implies a better indicator. 


\subsection{Exposure Estimates}

To estimate the exposure (energy production in GW-days/MT) of the fuel adjacent to a channel sample, the indicator isotope ratios within the sample volume must be calculated as a function of burnup. Since the exact bundle design was not available, reactor modeling efforts have been restricted to a generic 10×10 BWR bundle design. The assumptions used for this model are listed in Table 4.1.

Table 4.1. Generic $10 \times 10$ BWR Bundle

\begin{tabular}{cc}
\hline Parameter & Value \\
\hline $\mathrm{UO}_{2}$ Density & $10.5 \mathrm{~g} / \mathrm{cc}$ \\
${ }^{235} \mathrm{U}_{\text {Enrichment }}$ & $3.74 \%$ \\
Fuel Radius & $0.442 \mathrm{~cm}$ \\
Cladding Radius & $0.5025 \mathrm{~cm}$ \\
\hline Pitch & $1.34 \mathrm{~cm}$ \\
Channel Thickness & $0.3048 \mathrm{~cm}$ \\
Fuel Temperature & $1000 \mathrm{~K}$ \\
Clad Temperature & $600 \mathrm{~K}$ \\
Coolant Temperature & $550 \mathrm{~K}$ \\
Channel Temperature & $550 \mathrm{~K}$ \\
Coolant Density Range & $0.25-0.74 \mathrm{~g} / \mathrm{cc}$ \\
Exposure Range & $0-100 \mathrm{GWd} / \mathrm{MT}$ \\
\hline
\end{tabular}

In the absence of a known axial power shape or 3D core model, the exposure estimates must be regarded as local as opposed to bundle average. The WIMS-8 lattice physics code was used to calculate isotope ratios for titanium, hafnium, and iron in the channel as a function of fuel exposure. Figure 4.1 shows the calculated variation of the ${ }^{179} \mathrm{Hf} /{ }^{176} \mathrm{Hf}$ ratio in the channel as a function of exposure at several different coolant densities. Not surprisingly, the results are strongly dependent on coolant density, which depends on the location of the sample in core. 


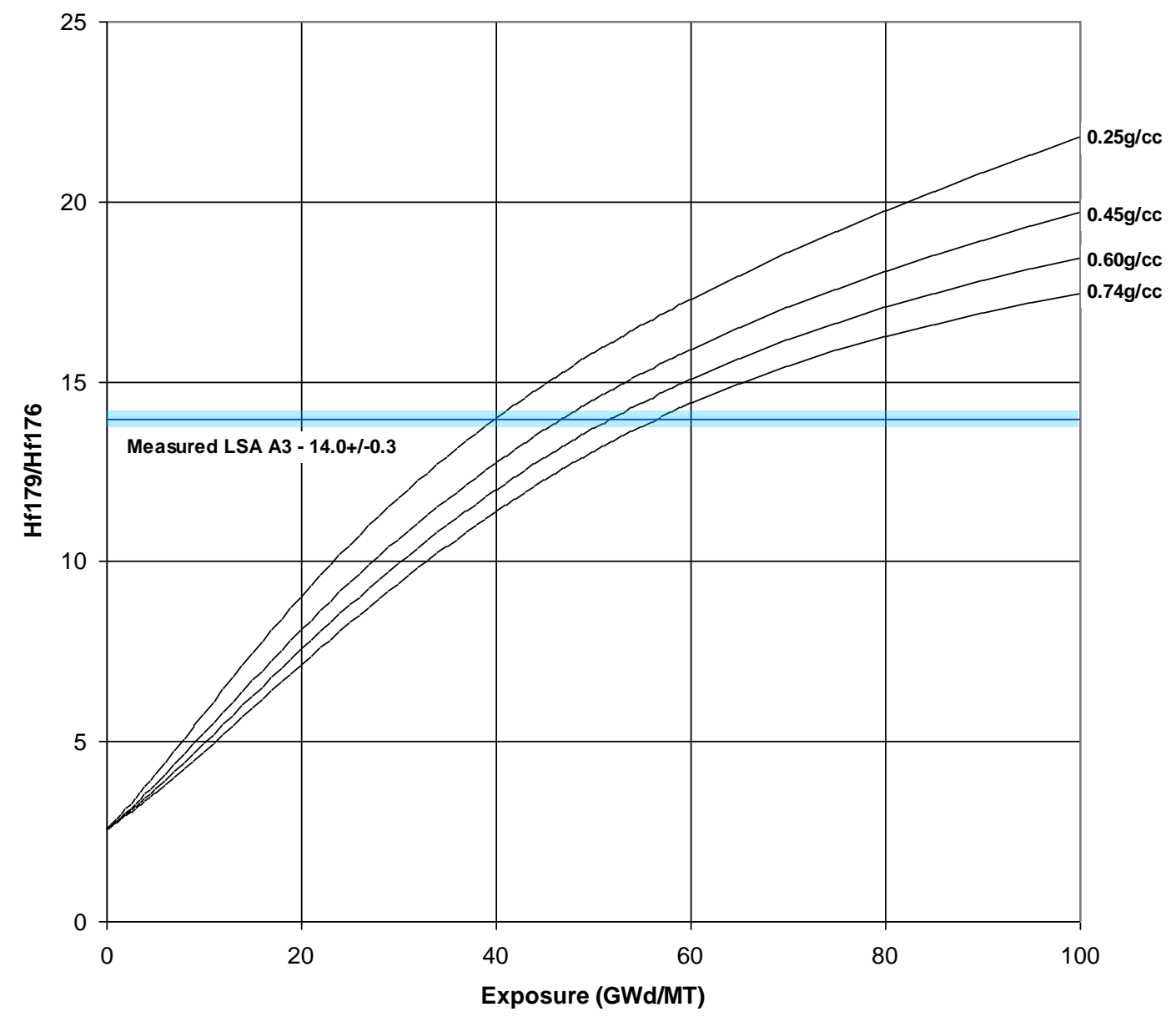

Figure 4.1. ${ }^{179} \mathrm{Hf} /{ }^{176} \mathrm{Hf}$ Ratio as a Function of adjacent Fuel Exposure

As can be seen in Figure 4.1, the measured ${ }^{179} \mathrm{Hf} /{ }^{176} \mathrm{Hf}$ ratio in sample LSA-A3 yields an exposure estimate that could vary from 40 to $57 \mathrm{GWd} / \mathrm{MT}$, depending on coolant density. However, by using estimates from other indicator elements, the actual water density can be inferred. This is illustrated in Figure 3.1.

Referring back to Figure 3.1, the exposure estimates for four different indicator ratios are plotted at three different values of water density. If all of the parameters in the model are correct, then all of the indicator ratios should yield the same exposure estimate. In this case, a water density of about $0.6 \mathrm{~g} / \mathrm{cc}$ produces the most consistent exposure estimates. It is interesting to note that both ${ }^{49} \mathrm{Ti} /{ }^{48} \mathrm{Ti}$ and ${ }^{56} \mathrm{Fe} /{ }^{57} \mathrm{Fe}$ are somewhat insensitive to the water density. This is in contrast to the one-dimensional pin-cell models used earlier in the project. In a more formal analysis, all of the measured ratios could be used in a regression to produce an overall estimate and uncertainty.

A second method to verify the consistency of the reactor model is to plot one indicator ratio against another and then overlay the measured data from all of the samples. If all the parameters in the reactor model are correct, the data points should lay on the calculated curve. This is shown in Figure 4.2 for the 
$0.6 \mathrm{~g} / \mathrm{cc}$ case. This figure shows good agreement between the measured (box icon) and calculated (continuous line) ratios.

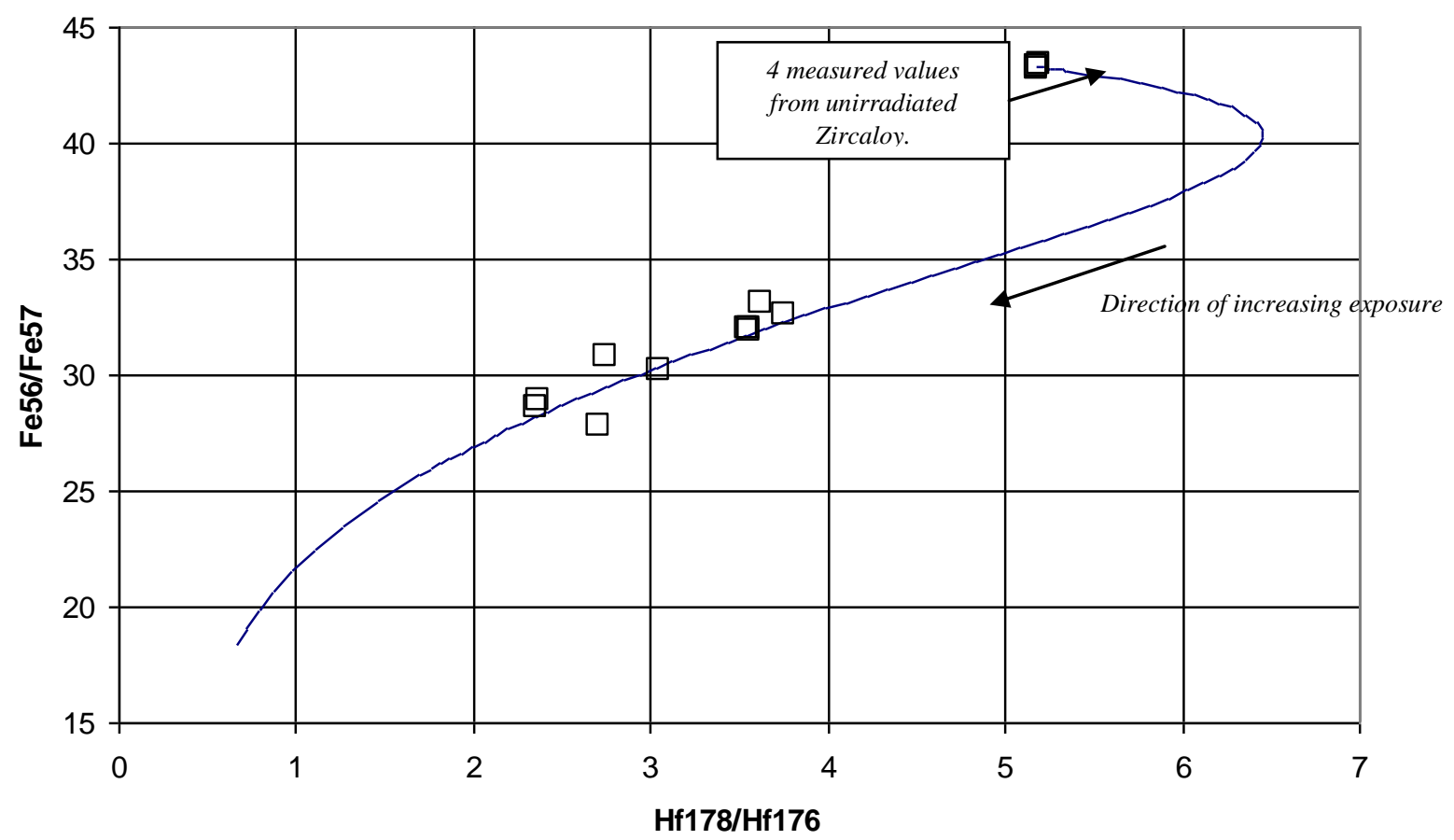

Figure 4.2. WIMS Calculated ${ }^{56} \mathrm{Fe} /{ }^{57} \mathrm{Fe}$ Versus ${ }^{178} \mathrm{Hf} /{ }^{176} \mathrm{Hf}$ with Measured Data

The SIMS measured data for all of the samples is provided in Table 3.2, and is plotted against a curve generated by WIMS in Figure 4.2. This data has been corrected for bias from natural isotopic ratios values by measuring four unirradiated Zircaloy samples.

The measured isotope ratio values were used to generate interpolated exposure estimates from the WIMS- 8 calculated curves at a water density of $0.6 \mathrm{~g} / \mathrm{cc}$. Additionally, the measurement errors were used to produce a corresponding error in exposure for each measured ratio. These errors do not address any errors associated with the calculational model. The results are shown in Table 4.2. 
Table 4.2. Estimated Sample Exposure (GWd/MT) by Indicator Ratio

\begin{tabular}{ccccccccc}
\hline Sample ID & ${ }^{49} \mathrm{Ti} /{ }^{48} \mathrm{Ti}$ & $2 \mathrm{SE}$ & ${ }^{178} \mathrm{Hf} /{ }^{176} \mathrm{Hf}$ & $2 \mathrm{SE}$ & ${ }^{179} \mathrm{Hf} /{ }^{176} \mathrm{Hf}$ & $2 \mathrm{SE}$ & ${ }^{56} \mathrm{Fe} /{ }^{57} \mathrm{Fe}$ & $2 \mathrm{SE}$ \\
\hline LSA A3 & 49.6 & 0.4 & 49.8 & 0.2 & 51.9 & 0.9 & 48.4 & 0.4 \\
LSA A3-2 & 49.3 & 1.9 & 49.6 & 0.2 & 52.3 & 0.6 & 47.3 & 0.5 \\
LSA A4 & 49.2 & 0.2 & 45.0 & 0.7 & 50.4 & 1.2 & 40.4 & 0.6 \\
LSA C1 & 36.7 & 0.2 & 36.7 & 0.4 & 38.3 & 0.7 & 36.4 & 1.2 \\
LSA C1-1 & 36.7 & 0.2 & 36.9 & 0.3 & 38.4 & 0.7 & 35.9 & 0.6 \\
LSA C1-2 & 37.0 & 0.3 & 36.7 & 0.4 & 38.4 & 0.7 & 36.0 & 0.6 \\
LSA C3 & 34.3 & 0.4 & 34.9 & 0.5 & 37.2 & 0.4 & 33.8 & 1.0 \\
SUS 23C & 54.2 & 0.7 & 45.5 & 0.8 & 46.0 & 1.1 & 51.5 & 1.5 \\
SUS 33A & 32.6 & 1.2 & 36.2 & 0.4 & 39.8 & 0.7 & 32.0 & 2.0 \\
SUS33C & 45.9 & 1.6 & 41.7 & 0.1 & 42.8 & 0.7 & 42.4 & 0.8 \\
\hline
\end{tabular}

In general, the different indicator ratios provide consistent results. However, it appears that ${ }^{178} \mathrm{Hf} /{ }^{176} \mathrm{Hf}$ is generally higher than the average and ${ }^{56} \mathrm{Fe} /{ }^{57} \mathrm{Fe}$ is generally lower. Table 4.3 provides an average exposure estimate based on all four indicator elements for each sample.

Table 4.3. Average Estimated Sample Exposure (GWd/MT)

\begin{tabular}{cc}
\hline Sample ID & GWd/MT \\
\hline LSA A3 & $50+/-1$ \\
LSA A3-2 & $50+/-2$ \\
LSA A4 & $46+/-5$ \\
LSA C1 & $37+/-1$ \\
LSA C1-1 & $37+/-1$ \\
LSA C1-2 & $37+/-1$ \\
LSA C3 & $35+/-2$ \\
SUS 23C & $49+/-4$ \\
SUS 33A & $35+/-4$ \\
SUS33C & $43+/-2$ \\
\hline
\end{tabular}

While exact exposures for the analyzed sample locations were not available, the declared range of fuel assembly average exposure was approximately 35 to $44 \mathrm{GWd} / \mathrm{MT}$. These results, which are local estimates, appear to be consistent with the bundle average exposures.

In summary, this work has demonstrated that reasonable exposure estimates can be generated from trace element isotope ratio measurements in Zircaloy. Additionally, the use of multiple indicator elements allows the water density at the sample location to be inferred, even when using an approximate, 2dimensional reactor model. These results warrant further work and suggest that trace element IRM of BWR channel samples can likely provide BWR fuel assembly exposure estimates with an accuracy of better than $10 \%$. 


\subsection{Purpose-built Monitor Design}

As discussed above, isotope ratio techniques were demonstrated on titanium and hafnium impurities in commercial Zircaloy alloys. Given enough time and a full-scale SIMS, analysis of impurities can easily identify any assembly that was "short-cycled" to produce plutonium as opposed to a full cycle for energy production. Purpose-built monitors are proposed to enable shorter measurement times and/or the use of miniaturized SIMS instruments for analysis at the reactor site. Purpose-built monitors can also be designed for easier, safer mechanical removal and handling compared to taking a sample of fuel assembly structural parts.

Rather than rely on trace impurities, the purpose-built monitors approach involves attaching a small tab, wire, or chip made of specific isotopes that have desirable nuclear, chemical, and ionization characteristics. One necessary nuclear characteristic is having at least two stable isotopes for isotope ratio measurements. Candidate isotopes have a thermal neutron capture cross-section low enough that they are not practically depleted during anticipated fuel assembly irradiation, have good corrosion resistance and chemical compatibility with the Zircaloy alloys in the fuel assembly and coolant, and have atomic weights significantly higher or lower than major interference species, which would cause problems during SIMS analyses.

\subsection{Material Properties}

Beyond desirable nuclear and SIMS analysis characteristics, the indicator material needs to have good corrosion behavior if it will be exposed to the reactor coolant. Review of the listed candidates for adequate corrosion resistance removed iron, osmium, and tungsten from consideration. Tungsten does, however, have the greatest change in isotope ratios and might be used in a monitor if the monitor were enclosed inside a clad tube. For the time being, we consider hafnium (Hf), titanium (Ti), and platinum $(\mathrm{Pt})$ to be the most practical choices.

\subsection{Physical Design}

The physical design of the indicator needs to measure flux along the entire axial length of the fuel assembly, remain in place during reactor operation, not interfere with fuel assembly movement during refueling, not reduce any safety margins, and be easily removable when desired. For LWR fuels intended for BWR, PWR and VVER reactors, the best physical design proposed so far is a wire or a wire flattened into a strip, which can be housed in a slot or "piggyback" tube on a guide tube for PWR or VVER, depending on whether the indicator wire can stand exposure to the reactor coolant.

Full development of a physical design will require in-reactor testing to verify that the mechanical design can survive in the reactor environment - for example threaded fasteners generally will seize and cannot be disassembled after three cycles in an LWR. Figure 5.1 shows the upper nozzle of a VVER fuel assembly, including three instrumentation tubes, one of which could be used to house an indicator wire. Similar instrumentation tubes exist in PWR and BWR fuel assemblies. 


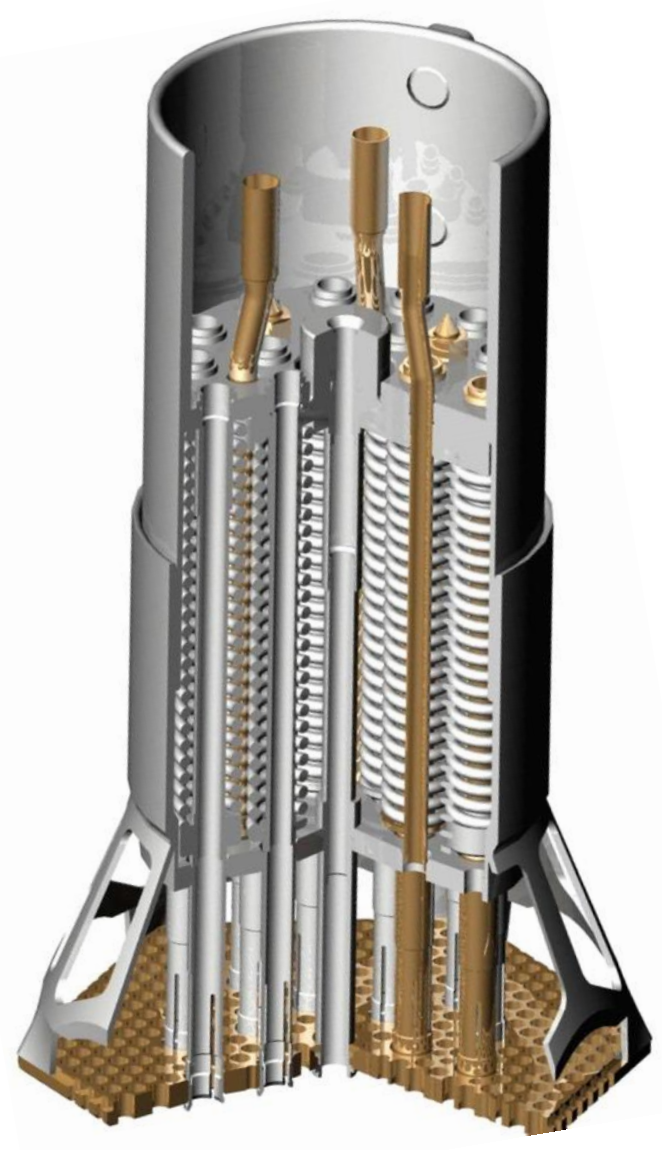

Figure 5.1. Upper Nozzle of VVER Fuel Assembly 


\subsection{Theoretical Studies of Purpose-Built Monitor Designs}

This project includes only theoretical studies of purpose-built monitor designs. As discussed above, titanium, hafnium and platinum show promise as monitor materials. Hafnium has several isotope pairs that can be used to measure fuel assembly exposure and has a long history of use in nuclear technology. Titanium, being in the same periodic table group as zirconium and hafnium, has similar corrosion resistance and has been the main element used in trace impurity IRM studies.

\subsection{Specific Recommended Analytical SIMS Protocols for Optimized Monitors}

The PNNL work led to six specific recommendations:

1. Obtain two or more lots of the selected high-purity material to support testing. Keep some in reserve to represent initial non-irradiated reference material.

2. For both non-irradiated material and irradiated monitors, mount a portion of the material in the standard SIMS sample holder and pre-sputter area for analysis using a primary ion beam of approximately 1 to 2 microamperes. This is necessary because surface impurities can be added or embedded when high-purity metals are formed or rolled into thin foils or filaments.

3. Conduct an elemental scan from hydrogen through plutonium or higher, with the high primary ion beam, to identify impurity elements and potential isobaric and molecular interferences. Conduct the element scan using the lower primary ion beam, with matrix element isotopes at approximately 500 thousand cps, to again assess impurity elements and interferences These interferences should be negligible, with the exception of MO+, MOn+, or Mn+. Switch to the ion-imaging mode and, using the lower-density primary ion beam, conduct a search for possible impurity-rich microscopic domains or inclusions in each chosen analysis spot. If present, select another spot for pre-sputtering and analysis.

4. In setting up a data-acquisition routine, select individual isotope counting times to optimize measurement precision. In general, longer counting times are required for low-abundance isotopes or for isotopes predicted to be low in abundance after burnup, relative to isotopes with lower cross sections.

5. In non-irradiated samples held in reserve as reference material, conduct replicate analyses to determine the optimum length of time for individual spot analyses and the optimum number of spot analyses required to minimize measurement uncertainty. Conducting these measurements will provide the initial starting values to use in neutronics modeling and plutonium production estimates. By measuring the reserved material from the same lot from which monitor materials were produced, SIMS instrument measurement mass bias, which can be up to several percent relative to certified values, can be disregarded. Long-term changes in measurement results on the non-irradiated reference material are of interest mainly for instrument maintenance and checking the ion-counting detection system on the SIMS.

6. Analyses of non-irradiated reserved reference samples should be conducted along with analyses of irradiated monitors. Long-term instrument drift may result in small changes in the measurement mass bias, and it is best to use recent or interleaved measurements to determine initial ratio values for calculations. The same analysis menu and isotope counting times should be used for both non- 
irradiated reference samples and irradiated monitors. Results for both monitors and non-irradiated starting material should be reported. 


\subsection{Conclusions}

The work described here has demonstrated that IRM techniques can be applied to trace impurities in commercial Zircaloy, yielding estimates of fuel assembly burnup to within $2 \mathrm{MWd} / \mathrm{MT}$, with $95 \%$ confidence. This is more than adequate accuracy to confirm declared operations of LWR reactors for non-proliferation purposes. Analysis of trace impurities can be applied to fuel assemblies regardless of how much time has elapsed since irradiation, and can be applied to any fuel assembly that uses zirconium alloy structural parts.

Theoretical work has been done to identify two, (titanium and hafnium) and possibly a third, (platinum) element that could be used for a purpose-built indicator, one which could be analyzed more rapidly and by less experienced SIMS operators compared to native impurities in the Zircaloy. Practical application of this technology will require testing and qualification of the purpose-built monitors for each type of fuel assembly that they are used on.

Work is ongoing to develop purpose-built monitors specifically applicable to CANDU reactor fuel assemblies. The fact that CANDU reactors refuel on-line makes fuel assembly diversion or short-cycle irradiation easier to do than in typical LWR reactors. The relatively large number of assemblies and the high throughput make the faster, easier analysis of a purpose built monitors particularly attractive. 


\subsection{References}

Gerlach DC, CM Heeb, KA Pauley, BD Reid, and RJ Talbert. 1998. GIRM Accuracy Calculations.” PNNL-RTC-0693, Rev. 1, Pacific Northwest National Laboratory, Richland, Washington.

Gesh CJ. 2004. A Graphite Isotope Ratio Method Primer: A Method for Estimating Plutonium Production in Graphite Moderated Reactors. PNNL-14568, Pacific Northwest National Laboratory, Richland, Washington.

Reid BD, WC Morgan, EF Love, DC Gerlach, SL Peterson, JV Livingston, LR Greenwood, and JP McNeece. 1999. Graphite Isotope Ratio Method Development Report. PNNL-13056, Pacific Northwest National Laboratory, Richland, Washington.

Walker WF, JR Parrington, and F Feiner. 1989. "Nuclides and Isotopes," $14^{\text {th }}$ Edition, General Electric. 